\title{
Ensayo
}

\section{Zombis, alienígenas y rockeros: Sergio Roncallo-Dow en el espejo retrovisor}

\section{Carlos A. Scolari ${ }^{1}$}

DOI: $10.5294 /$ pacla.2020.23.s.5

Para citar este ensayo / to reference this essay / para citar este ensaio Scolari, C. A. (2020). Zombis, alienígenas y rockeros: Sergio Roncallo-Dow en el espejo retrovisor. Palabra Clave, 23(supl.), e23s5. https://doi.org/10.5294/pacla.2020.23.s.5

\section{Resumen}

Con una serie de citas, recuerdos, entrevistas y apuntes, el autor se propone reconstruir las contribuciones del filósofo, investigador y profesor Sergio Roncallo-Dow a los estudios de la comunicación en el contexto iberoamericano. A lo largo de su carrera académica, la particular mirada de Sergio lo llevó a abordar diferentes objetos de estudio y de reflexión, basándose en un personal trípode que se asentaba en la historia de la filosofía, las teorías de las comunicación y la cultura pop. Es este espíritu híbrido y transdisciplinario el que se quiere poner en evidencia en este texto tributo. Porque, así como hay bandas tributo, también hay textos tributo que aspiran a reinterpretar las mejores canciones de un artista.

\section{Palabras clave}

Sergio Roncallo; teorías de la comunicación; géneros; ciencia ficción; McLuhan.

1 https://orcid.org/0000-0002-7792-0345. Universitat Pompeu Fabra, España. carlosalberto.scolari@upf.edu 
¿Es posible resumir los aportes de un filósofo e investigador de la comunicación en cuatro mil o cinco mil palabras? ¿Cómo hacerlo cuando estamos hablando de un pensador inclasificable, que entraba y salía de las solemnidades del registro académico con la misma facilidad que subía y bajaba de un escenario con su Gibson blanca?

La mejor manera de re-leer a Sergio Roncallo-Row (de aquí en más Sergio) es con una pantalla interactiva a mano para chequear las películas, los cómics, los videojuegos y las canciones que a menudo dejaba caer en cada párrafo. Sí, re-leer a Sergio siempre ha sido y seguirá siendo un ejercicio de lectura transmedia (Albarello, 2019).

En las próximas páginas, trataré de reconstruir ese mosaico intelectual de la única manera posible: juntando fragmentos textuales, recurriendo a los recuerdos y suspirando por las piezas que quedaron fuera del tablero y nunca más recuperaremos.

\section{Espejo retrovisor}

Digámoslo claramente: Más allá del espejo retrovisor: la noción de medio en Marshall McLuhan (Roncallo-Dow, 2011) es una obra de alta densidad filosófica donde Sergio pone a dialogar a Marshall McLuhan con las obras de Aristóteles, Heidegger, Husserl, Leroi-Gourhan, Mitcham, Piscitelli, Platón, Rancière, Sloterdijk, Vattimo y Wittgenstein, entre muchos otros filósofos y teóricos de la comunicación. El libro de Sergio se abre con una cita de Steiner a propósito de su relación con los textos del canadiense: "Los escritos de Marshall McLuhan están tan llenos de novedad, fuerza de sugestión, vulgaridad intelectual y descuido que uno se siente tentado enseguida a dejarlos de lado" (Roncallo-Dow, 2011, p. 13).

A continuación entra en escena Sergio:

Es posible que Steiner tuviera razón. Leer a McLuhan es complejo y, muchas veces, desalentador. En efecto, sus textos están llenos de reiteraciones, de referencias no explicadas y acude a la tradición literaria y filosófica como mejor le conviene. Un scholar ortodoxo diría que McLuhan es un pensador poco riguroso, que no respeta las fuentes 
originales y deforma la intención de los autores con los que trabaja. Pero, justamente esto es lo más valioso de su trabajo: la filosofía, la literatura o todo lo que sea que leamos, debe servir para pensar. Eso lo sabía McLuhan. (Roncallo-Dow, 2011, pp. 14-15)

También lo sabía Sergio. Ahora que repaso su producción teórica y su actividad científica, emerge muy claro que Sergio se movió en ese espacio tensionado que se abre entre el mundo académico "ortodoxo" y su periferia, esas zonas de frontera donde se producen hibridaciones con otros sistemas de pensamiento y acción.

Volvamos a Más allá del espejo retrovisor. A treinta años de la muerte de McLuhan (acaecida en diciembre de 1980, mientras en las pantallas televisivas daban sus primeros pasos CNN y MTV, y Steve Jobs ya estaba trabajando en el Macintosh, la computadora for the rest of us que lanzaría en 1984), Sergio tomaba nota de "la re-configuración del mundo que habitamos, y el modo en el que la técnica se ha complejizado a un punto tal que ha re-dispuesto nuestra forma de comprendernos y de comprender el entorno propio. Actualmente, la opacidad de los escritos (de McLuhan) cobra una luz inusitada” (Roncallo-Dow, 2011, p. 14).

Este revival, según Sergio, obedece a que McLuhan "ha sido de los pocos pensadores del siglo XX capaz de pensar en toda su densidad el fenómeno de lo técnico que, paulatinamente, ha empezado a tener cierta relevancia dentro del sistema filosófico contemporáneo" (Roncallo-Dow, 2011, p. 14).

Para terminar con esta serie de citas, hay un párrafo de Más allá del espejo retrovisor donde Sergio habla de McLuhan, pero, agrego yo, podría estar haciéndolo de sí mismo:

Las propuestas de McLuhan no fueron tomadas en serio por muchos de sus contemporáneos, quienes los consideraron más una estrella de la cultura pop [...] que un pensador digno de ser tenido en cuenta; sus inquietantes teorizaciones sobre los mass media y difícil e intrincada forma de escribir y de pensar — como una sonda, según sus propia palabras - han hecho de su figura una especie de signo ambivalente que se debate entre lo ligero y lo oscuro, entre lo riguroso y lo light. (Roncallo-Dow, 2011, p. 14) 
Si miramos en un espejo retrovisor el recorrido de Sergio, descubriremos que él también vivía en carne propia esa ambivalencia y se debatía "entre lo ligero y lo oscuro, entre lo riguroso y lo light". Al repasar su obra, encontramos producciones académicas que se erigen como puntos de anclaje científico de altísimo rigor, desde Más allá del espejo retrovisor, un libro de reflexión filosófica digno de un scholar de una universidad de la Ivy League, hasta Estudiar las audiencias: tradiciones y perspectivas, un completísimo mapa de la investigación de audiencias escrito junto con Manuel Ignacio González-Bernal y Germán Arango-Forero (2018), por no mencionar su trabajo como editor de la Revista Palabra Clave (al cual, por su relevancia, le dedicaremos una sección específica de este artículo mosaico).

Pero a Sergio ese sistema científico-académico no lo podía contener: ese mundo le quedaba chico, y como las "sondas" de McLuhan, andaba siempre experimentando líneas de fuga. Y es aquí que descubrimos, sin sacar la vista del mismo espejo retrovisor, una producción textual mestiza que comparte con la obra de McLuhan, y otros pensadores como Alessandro Baricco, un explosivo espíritu de marginalidad creativa que caracteriza a los outsiders.

\section{La Silla Eléctrica (1)}

Encuentro en la web un cuestionario del desaparecido programa de la Radio Nacional de Colombia La silla eléctrica donde Sergio reconstruye, a golpe de datos y apuntes personales, una autobiografía muy íntima.

\section{Nombre completo y apellidos}

Sergio Roncallo-Dow.

\section{Fecha y lugar de nacimiento}

17 de marzo de 1979 ... Día de san Patricio, lo que explica muchos de mis comportamientos...

\section{Breve biografía}

Nací en Bogotá hace ya casi tres décadas. Fui un niño muy silencioso y con pocos amigos. Mi actividad favorita era hacer tareas. A los 11 años descubrí la guitarra y desde entonces he tratado de convertirme en estrella de rock... Como es manifiesto que eso no pasaría 
de ser un sueño, estudié filosofía y comunicación hasta convertirme en una especie muy particular y precaria de profesor, lo que por cierto, me ha hecho muy llevadera la existencia. (La Silla Eléctrica, s. f.)

\section{Claves de una palabra}

La noticia de la muerte de Sergio me llegó durante la primera semana de confinamiento por el coronavirus en España. Es como si se hubiera negado a quedar eclipsado por la curva estadística. Esa mirada que tiende a cuantificar todo, desde el valor de una publicación científica hasta la performance de un investigador o la cantidad de fallecidos por una pandemia, era uno de los temas permanentes de mis conversaciones con Sergio. Con él y otros colegas, nos tomábamos a mofa los largos tiempos de evaluación de los artículos científicos o las ridículas respuestas de algunos editores o revisores. Por no hablar de las publicaciones que se han convertido en decadentes máquinas endogámicas de promoción bibliométrica.

Más allá de estas críticas al sistema, con Sergio compartíamos un sentimiento ambivalente: los dos nos sentíamos disconformes con un paradigma exclusivamente cuantitativo de valoración de la producción científica, pero estábamos obligados a jugar en esa liga si queríamos obtener el reconocimiento de los sistemas nacionales de evaluación. Como la democracia, a pesar de sus taras, el sistema de valoración cuantitativo de la investigación parece ser el menos malo de todos. Pero que se podría mejorar, no quedan dudas.

En este contexto, Sergio logró lo imposible: posicionar una revista latinoamericana en el índice Scopus, Elsevier y Web of Science (WoS) de Clarivate Analytics. Porque hay que decir las cosas como son, una publicación científica es el resultado del trabajo de cientos de autores y revisores, una red de investigadores que dedica muchas horas de su tiempo a mantener en funcionamiento y alimentar una hambrienta criatura académica, pero el rol del editor es fundamental. Podría decirse que, como en el mundo del periodismo, cada editor le da su toque personal a una publicación científica. En este sentido, bajo la dirección de Sergio, la Revista Palabra Clave abordó temas de frontera que hasta entonces la academia iberoamericana apenas había explorado. 
Podría decirse que 2015 fue un buen año para la ecología de los medios en lengua española: ese año Gedisa publicó mi recopilación Ecología de los medios: entornos, evoluciones e interpretaciones - donde Sergio participó junto con Diego Mazorra con un capítulo titulado "Ecología, arte y política: la estética como control (contra) ambiental”- y la Revista Palabra Clave dedicó un monográfico a esa disciplina con contribuciones de Eric y Marshall McLuhan, Mario Carlón, Sandra Valdettaro, Octavio Islas y el autor de estas líneas, entre otros investigadores. Cualquier estudiante o académico interesado en este campo deberá pasar por estos textos si quiere ir más allá de la bibliografía clásica en inglés.

Pero no solo la mirada ecológica: la publicación en 2017 del monográfico sobre cultural transduction coordinado por Enrique Uribe-Jongbloed y Hernán David Espinosa-Medina, o el volumen dedicado a los fan studies a cargo de Mar Guerrero-Pico, Maria-José Establés y Maria-Jose Masanet, son buenos ejemplos de esta introducción de nuevos conceptos, enfoques y objetos de estudio en el circuito académico iberoamericano por parte de la Revista Palabra Clave durante la dirección de Sergio.

Estoy convencido de que este esfuerzo de Sergio por llevar al centro del régimen de producción científica conceptos que nacían en su periferia o directamente ir a buscar objetos de estudio marginales como la fanfiction, será valorado como corresponde por la comunidad académica iberoamericana. También espero que la valentía profesional que demostró al encarar esas exploraciones en cuando editor de un journal científico sea tan contagioso como su vivacidad intelectual y apertura mental.

\section{La Silla Eléctrica (2)}

\section{Programa de TV favorito en su infancia}

Topacio (telenovela en la que me enganché estando enfermo de hepatitis, por allá a mediados de los ochenta), El precio es correcto, Automan, Manimal y los inigualables Magnificos.

\section{Bebida favorita}

El Vodka Absolut con Sprite, aunque suene guayigol... También están el jugo de maracuyá y la Canada Dry. 


\section{¿Qué le da miedo?}

Casi todo... soy algo cobarde. En mi infancia me causaban particular animadversión y temor los perros, hoy lo he superado y le temo mucho más a ciertos seres humanos. (La Silla Eléctrica, s. f.)

\section{Pop theory}

El inicio del prólogo de Volver a los clásicos: teorías de la comunicación y cultura pop (Roncallo-Dow et al., 2016), un ejercicio colectivo de escritura, es un programa de investigación a todos los efectos:

Este libro nace, esencialmente, de la intuición. Durante algún tiempo
nos preguntamos si era más adecuado explicar ciertos fenómenos
sociales leyendo a Foucault o yendo a un Comic-Con. Nos lo pregun-
tábamos, sobre todo, porque cada vez resultaba más difícil entender
el modo en el que nuestros estudiantes comprendían la realidad. El
ejercicio de la exégesis de textos "clásicos" resultaba cada vez más
estéril, pero, a la vez, la pura alusión a los fenómenos propios de la
vida contemporánea dejaba escapar toda la riqueza del análisis que,
desde las teorías de la comunicación, se había hecho durante el siglo
XX. (p. 17)

Los autores detectaban un gap entre las teorías de la comunicación, los eventos socio-tecno-culturales que las habían generado y el paisaje mediático contemporáneo. Me viene un ejemplo a la memoria: ¿qué significado tiene para un millennial leer una famosa bibliografía obligatoria escrita hace ochenta años en que un complicado filósofo alemán cargaba las tintas contra el ritmo del jazz? La revisión teórica que se propone en Volver a los clásicos, como dicen los autores, está inscrita en

un entorno mediático de ovnis y alienígenas, láminas autoadhesivas que Ilenan álbumes sobre eventos futbolísticos, pantallas omnipresentes de YouTube atestadas de videomusicales y series televisivas que salen de la pantalla plana del Smart TV a ocupar repositorios digitales casi infinitos y ser consumidas a través de teléfonos móviles 0 tabletas portátiles. (Roncallo-Dow et al., 2016, p. 17)

Quiero ser claro: los autores no están proponiendo desterrar las “viejas" teorías de la comunicación, sino releerlas desde la nuevas prácticas mediáticas, porque comprender la comunicación desde los clásicos "es com- 
prender la modernidad" (Roncallo-Dow et al., 2016, p. 17). Pero hay algo más: el juego lúdico que se practica en cada página es una experiencia en sí misma. En su reseña de Volver a los clásicos, Arango (2017) escribió que leer este libro "es ya una experiencia. La multiplicidad de voces, el cambio de primera a la tercera persona, la conmutación entre el 'yo' y el 'nosotros', y la excelente narración, harán de su lectura algo retador y, por lo mismo, divertido" (p. 568).

En este contexto, releer a Hadley Cantril y Charles Wright Mills desde los alienígenas, entrar en la discusión estructuralista a partir de los videoclips, mirar YouTube sentados junto a Walter Benjamin o repasar los álbumes de figuras futbolísticas desde la perspectiva de la escuela de Fráncfort son algunos de los estimulantes ejercicios analíticos que nos propone un volumen que, como escriben los autores, "lleva a los lectores valientemente a tiempos a los cuales ninguno ha ido jamás y luego de regreso al futuro" (Roncallo-Dow et al., 2016, p. 20).

\section{La Silla Eléctrica (3)}

\section{Frase que más detesta}

"Profe, ¿esto toca leerlo para el parcial?"

\section{Música favorita}

Desde Def Leppard, Poison, Metallica y Dio hasta Queen y Enrico Macias.

\section{Una pasión}

No una, tres: enseñar, tocar la guitarra y el hard rock de los ochenta. (La Silla Eléctrica, s. f.)

\section{Zombis y guitarras}

Sergio trabajó hasta el fin. En los últimos meses estaba escribiendo algo "sobre zombis" - nunca me dio detalles, no sé si era un libro o un artículo- y me envió cuatro preguntas muy específicas para alimentar ese trabajo. Las comparto aquí para que se vean el tipo de asociaciones temáticas que solía hacer Sergio: 
Sergio: ¿Cuáles son tus tres películas de zombis favoritas?

CAS: Si bien he seguido The Walking Dead durante varias temporadas, el género de zombis no es precisamente uno de mis favoritos (por ejemplo, encuentro mucho más interesantes las historias de alienígenas). Por lo tanto, mi elección es muy clásica. Seguramente, la obra fundacional de George Romero (La noche de los muertos vivientes) abre mi lista. Soy leyenda es una de mis películas favoritas (también del resto de la familia Scolari). Cuando estuvimos en New York, nos divertimos mucho buscando las localizaciones de ese largometraje. Finalmente, mi tercera opción no la tengo para nada clara: pondría películas como REC, 28 días después y, si me lo permiten, el primer episodio de The Walking Dead, que es realmente excelente. Por otra parte, no debemos olvidar que en Kill Bill: Volume 2 Uma Thurman es enterrada viva y sale de la tumba sedienta de sangre, lo cual no deja de ser un gesto típico de los zombis.

Sergio: ¿Hay autocensura en las redes sociales?

CAS: La comunicación en las redes sociales tiene muchas características de la comunicación oral (es efímera, impulsiva, conversacional), por lo que a veces no se reflexiona mucho sobre el contenido de esos intercambios. ¿Quién no se ha pasado de revoluciones en algún intercambio y termina perdiendo "amigos" o borrando un tuit? Por otro lado, existen otros contenidos - pienso en las fotografías muy trabajadas en Instagram, por ejemplo los selfies- donde el creador o creadora ha tenido tiempo de reflexionar con calma y se pierde ese carácter efímero y veloz que caracteriza otras producciones. Las redes sociales son un fenómeno relativamente reciente que evoluciona de manera acelerada; todos, jóvenes y adultos, estamos aprendiendo (un poco a los tumbos) a vivir en estos nuevos entornos interactivos. A medida que aprendamos a utilizarlas, es probable que seamos más cautos y controlemos mejor los contenidos antes de compartirlos. 0 no.

Sergio: ¿Cómo ves hoy el papel de la corrección política en el ejercicio del discurso público?

CAS: La corrección política implica dejar de decir cosas. Ahora bien, en la actualidad las conversaciones políticas se están degradando de manera acelerada. Lo peor de los intercambios en las tertulias televisivas o las redes sociales ha permeado las prácticas discursivas en el ámbito de la política. Sin embargo, como decía Foucault, "no se puede decir todo", tienen que existir mecanismos de exclusión y reglas del discurso. En ese contexto, que haya un retorno a cierta racionalidad discursiva política (donde "no se pueda decir todo") sería algo positivo. Pero, por otra parte, llevada a sus extremos, la correc- 
ción política puede terminar ocultando tantas cosas que se convierte en hipocresía. El discurso político se vuelve aséptico, pasteurizado. Por lo tanto, creo que una dosis de incorrección política es bienvenida cada tanto para replantar discusiones, desmontar hipocresías y enriquecer el debate público.

Sergio: ¿Son los influencers los nuevos líderes de opinión?

CAS: Son actores emergentes de la nueva ecología mediática. Tienen algo de los viejos líderes de opinión estudiados por la mass communication research (son referentes especializados en algún tema que pueden llegar a condicionar nuestras elecciones), pero el contexto, las dinámicas y prácticas son muy diferentes. Los viejos opinion leaders se movían en un entorno mediático marcado por el broadcasting, ahora vivimos en el networking, y eso cambia todo. Más que two-step-flow of communication, ahora tenemos un multi-flow. (S. Roncallo-Dow, comunicación personal, 4 diciembre 2019)

A partir de estas preguntas podemos deducir que Sergio no estaba trabajando en algo exclusivamente "sobre zombis": imagino un texto sobre que los muertos vivientes se cruzaban con las redes sociales, los influencers y la insoportable levedad de la corrección política. ¿Qué tipo de amalgama vinculaba estos cuatro temas? ¿Cuáles conexiones neuronales estaban detrás de esta trama a primera vista ininteligible? Creo que nunca lo sabremos.

Lo que sí percibimos como lectores es que, además de la sintonía fina con las obras de McLuhan, una sinapsis invisible une los textos de Sergio con dos indispensables e influyentes ensayos de Alessandro Baricco-me refiero a Los bárbaros: ensayo sobre la mutación (2008) y The Game (2019)—, probablemente el intelectual más atrevido y menos prejuicioso a la hora de comprender las mutaciones culturales de la sociedad contemporánea. Pero si Baricco entra en las prácticas videolúdicas de las nuevas generaciones de la mano de la literatura, Sergio lo hacía con un sólido background teóricofilosófico en una mano y la Gibson Explorer en la otra.

Hablemos de la Gibson. Siempre me quedé con las ganas de sentir en vivo a Los Pussylánimes, el grupo de Sergio. Un amigo en común una vez en Chile me regaló un CD del grupo. Si bien yo soy más de Fender, me hubiera encantado escuchar en algún tugurio de Bogotá los riffs que salían de 
esa Gibson Explorer blanca, una guitarra de por sí rara que, encima, era un modelo left handed para músicos zurdos. A su manera, Sergio era también un explorer que circulaba por la izquierda, a contramano del flujo mainstrean del tránsito académico.

Hay una canción de Los Pussylánimes que encarna musicalmente la forma de trabajar la reflexión filosófica y la creación teórica que caracterizaba a Sergio. Me refiero a Stairway to Amor, un tema donde las guitarras y las voces, como ya nos tenía acostumbrados Sergio en sus textos académicos, entran y salen del clásico de Led Zeppelin Stairway to Heaven para intercalar, en medio del cover, otras voces, ritmos y sonidos. De la misma manera, Sergio también iba y venía entre lo científico y lo pop, entre lo ligero y lo oscuro, entre lo riguroso y lo light, entre Led Zeppelin y The Walking Dead, entrando por la filosofía y saliendo por una película de serie B.

\section{La Silla Eléctrica (4)}

\section{¿Qué consejo les daría a los jóvenes?}

Como no sé dar consejos, me dedico a enseñar. Es mucho más fácil.

\section{Último libro leído (no vale Cien años de soledad)}

La espuma de los días de Boris Vian...

\section{Equipo de fútbol}

Por supuesto, Independiente Santa Fe. (La Silla Eléctrica, s. f.)

\section{Espejo retroviral}

Por más que uno se esmere, resulta imposible reconstruir todas las piezas que componen la vida de una persona. En el caso de Sergio, son muchas las preguntas sin contestar... ¿Cuántas páginas quedaron sin escribir? ¿Cuántas canciones quedaron sin tocar? ¿Qué libros sin leer quedaron en lista de espera?

Si giramos el espejo retrovisor y miramos hacia el futuro, supongo que a Sergio le hubiera encantando escribir sobre estos tiempos de pandemia y confinamiento en que revivimos escenas vistas en el cine o en los cómics 
una y otra vez. Los fanáticos de la cultura pop y la narrativa apocalíptica no podemos salir de nuestro asombro al ver en las pantallas de este perverso 2020 imágenes que, hasta hace no mucho, nos deleitaban en las series, las películas, los cómics y los videojuegos que tanto amamos.

Hoy, más que nunca, necesitamos desarrollar un pensamiento científico-filosófico híbrido, mestizo, que nos permita repensar el nuevo mundo en el que estamos entrando. Como hacía Sergio, debemos aprender a entrar por una puerta y salir por otra, saltar de un sistema de pensamiento a otro, bascular entre la cultura del paper y la cultura pop, entrándole a la realidad de contramano y con instrumentos analíticos y teóricos tan filosos como el solo de una Gibson Explorer blanca.

\section{La Silla Eléctrica (5)}

\section{¿Cómo se ve en diez años?}

Espero que menos precario y ojalá no convertido en un dinosaurio de las aulas...

\section{¿Qué le pediría a un genio si se le apareciese?}

Que desapareciera.

\section{¿Qué lo irrita?}

Muy pocas cosas: el ruido cuando debe haber silencio y el silencio cuando debe haber ruido.

\section{Referencias}

Albarello, F. (2019). Lectura transmedia: leer, escribir, conversar en el ecosistema de pantallas. Ampersand.

Arango, C. A. (2017). I'll be back. Palabra Clave, 20(2), 567-570. http:// dx.doi.org/10.5294/pacla.2017.20.2.11

Baricco, A. (2008). Los bárbaros: ensayo sobre la mutación. Anagrama. 
Baricco, A. (2019). The game. Anagrama.

González-Bernal, M. I., Roncallo-Dow, S. y Arango-Forero, G. (2018). Estudiar las audiencias: tradiciones y perspectivas. Universidad de La Sabana.

La Silla Eléctrica. (s. f.). Sergio Roncallo-Dow. http://www.lasillaelectrica. com/sergio.htm

Roncallo-Dow, S. (2011). Más allá del espejo retrovisor: la noción de medio en Marshall McLuhan. Pontificia Universidad Javeriana.

Roncallo-Dow, S. y Mazorra, D. (2015). Ecología, arte y política: la estética como control (contra) ambiental. En C. A. Scolari (Ed.), Ecología de los medios. (pp. 263-294). Gedisa.

Roncallo-Dow, S., Uribe-Jongbloed, E. y Goyeneche-Gómez, E. (2016). Volver a los clásicos: teorías de la comunicación y cultura pop. Universidad de La Sabana.

Scolari, C. A. (Ed.) (2015). Ecología de los medios: entornos, evoluciones e interpretaciones. Gedisa. 